\title{
Parameter Improvement of the Soccer League Competition Algorithm by Introducing Stubborn Players: Application to Water Distribution Network
}

\author{
Godfrey Chagwiza, ${ }^{1}$ Absalom Jaison, ${ }^{2}$ and Tavengwa Masamha ${ }^{3}$ \\ ${ }^{1}$ Department of Applied Mathematics, National University of Science \& Technology, P.O. Box AC939, Ascot, Bulawayo, Zimbabwe \\ ${ }^{2}$ Department of Mathematics, Chinhoyi University of Technology, P. Bag 7724, Chinhoyi, Zimbabwe \\ ${ }^{3}$ Department of ICT, Chinhoyi University of Technology, P. Bag 7724, Chinhoyi, Zimbabwe \\ Correspondence should be addressed to Godfrey Chagwiza; chagwizag@gmail.com
}

Received 11 October 2015; Revised 15 February 2016; Accepted 28 February 2016

Academic Editor: Huaguang Zhang

Copyright (C) 2016 Godfrey Chagwiza et al. This is an open access article distributed under the Creative Commons Attribution License, which permits unrestricted use, distribution, and reproduction in any medium, provided the original work is properly cited.

A modified soccer league algorithm is presented in this paper. The effect of stubborn fixed players is investigated and the algorithm is implemented to three benchmark water distribution networks. The modified algorithm is compared to several algorithms. The results show that the modified algorithm performs better than the soccer league competition algorithm, in particular, on the average number of evaluations required to find the optimal cost. Computational results show that the utility benefit of both the individual player and team is essential. The algorithm becomes more reliable when utility benefits are high and as the number of fixed players increases.

\section{Introduction}

Optimization techniques have been in recent years regarded as important in line with technological advancement. The reliability of these optimization techniques is essential in real world applications [1-4]. Some techniques have been introduced to improve system reliability such as the techniques that increase reliability of system components and using redundancy components in many different subsystems [5]. Several hybrid algorithms have been introduced to improve performance of heuristics such as genetic algorithms [6], simulated annealing [7], ant colony optimization system [8], and particle swarm optimization [9].

Metaheuristic algorithms have been in recent years used to solve water distribution systems such as Max-Min Ant System [10], soccer league competition (SLC) [11], harmony search optimization approach [12], and shuffled frog leaping algorithm [13]. This research is motivated by the success of the soccer league competition algorithm of Moosavian [11] to solve water distribution network problems.
The remainder of the paper is organised as follows. In Section 2, a review and modification of SLC algorithm is presented. Implementation of the modified SLC algorithm is done in Section 3 and conclusions are drawn in Section 4.

\section{Review and Modification of Soccer League Competition (SLC) Algorithm}

The successful implementation of the Soccer League Competition algorithm of Moosavian [11] to solve water distribution network motivates this research. The soccer league algorithm's ideas are based on the soccer league and competition among players and teams and is relatively new but its promising results have motivated this research to explore the possibilities of expansion of the algorithm. The soccer league algorithm has the following steps.

Step 1. Initialisation of the problem and algorithm parameters: this involves defining the objective function and decision 
variables. The number of seasons, teams in the league, fixed players, and substitutes are determined in this step.

Step 2. Samples generation is carried out in this step of the algorithm. The total number of players in the league is calculated.

Step 3. Teams assessment is done by first arranging players according to their power. The power of each team is equal to the summation of power of each fixed player in the team.

Step 4. The league starts and competitions are initialised between all possible pairs of the teams that are in the league. Winners and losers in each match are determined. Imitation operator is introduced to fixed players in the winning team. The solution vector related to the fixed players in the team is regarded as moving toward the best solution vector of the league. A new fixed player is generated based on the solution vector of the winner team's fixed players. Provocation operator is introduced to screen the substitutes. The substitutes need to prove that they are better than the fixed player in the winner team. A new solution vector of substitutes in the winner team moves toward the solution direction of the fixed players. If the new solution vector generated is better than the older solution vector, the old solution vector is replaced (see Moosavian [11] for details).

Step 5. League update is done after every season. The players are arranged taking into account their updated power. Best players are allocated to best teams, average performers to average performing teams, and weakest players to bottom teams in the league table.

Step 6. Steps 3, 4, and 5 are repeated until the number of seasons required is achieved. Relegation of weakest teams and promotion of better performing teams take place.

The third step of the SLC algorithm is modified in order to achieve a better assessment of the teams in the league. Since power of fixed players in the team is used to determine the power of the teams, an attempt to incorporate stubbornness among the fixed players is carried out. It is a fact that most super star players become stubborn due to praises and they are usually assured of their fixed player status in most teams. It is therefore imperative to include this fact in the metaheuristic so as to improve its performance. Definitions of terms that are used are presented in "Definitions of Terms" section.

The team power is basically defined as the average power of its fixed players. The algorithm of Moosavian [11] did not incorporate the possibility of stubborn players. Stubborn players have an effect on the power of team which is an important aspect of the SLC algorithm. Team power is the most important part of winning the game. The power of player, as defined in the SLC algorithm, $P_{i, j}$, is

$$
P_{i, j}=\frac{1}{F_{i, j}}, \quad i \in T, j \in J .
$$

Incorporating the proposed effect of the stubborn players into (1) is presented as follows. We start by looking at the utility function of the team, $T$, which is given as follows:

$$
U_{i}=B_{m}-C_{m}+b .
$$

The team's performance can be affected by bribes given to either the couch or player or both. The utility function of the individual player is presented by (3) taking note of the effect of bribe. Bribes cannot be neglected when we are talking of soccer games:

$$
U_{j}=\alpha \pi+H-\beta W_{m}-b .
$$

Using (1) to (3), the power of an individual player can be formulated as in (4) since performance of an individual player is affected by the behavior of the couch toward each game:

$$
P_{i, j}=\frac{1}{F_{i, j} \times \gamma\left[U_{i}+U_{j}\right]} .
$$

The total team power is based on the power of each fixed player. It is therefore important to find the probability that the stubborn player secures the fixed position in the team. The probability that a stubborn player secures a fixed position in the team can be calculated as follows:

$$
\begin{aligned}
\epsilon(j)= & \widetilde{\eta}(\sigma) \delta\left(x_{j}\right) R+\left(1-\delta\left(x_{j}\right)\right) Q \\
& +[1-\widetilde{\eta}(\sigma)] x_{j} E-Q .
\end{aligned}
$$

Now, the total team power can be calculated by the following:

$$
Y_{i}=\frac{1}{N_{i}} \sum_{j=1}^{N_{i}} \epsilon(j) P_{i, j} .
$$

Figure 1 shows the flow chart of the modified soccer league algorithm.

\section{Numerical Examples}

Implementation of the modified soccer league algorithm is carried out in this section. Formalisation of steps required for comparing metaheuristics is important. In Chiarandini et al. [30], two main models were introduced and these are the univariate and multivariate models taking into account the solution cost and run time. There are good practices required to fairly compare metaheuristics. It is important to use benchmark problems [31]. It is also vital to present results in a way that allows fair comparisons of metaheuristics. These include showing execution time and the mean number of iterations to obtain the best result. The execution time and quality of solution are regarded as the main performance measures of primary interest. McGeoch [32] presents a detailed explanation of experimental analysis of algorithms.

In this paper, these best practices are implemented for a fair and effective comparison of the proposed modified heuristic with the other heuristics available in the literature. Three benchmark problems, that is, the two-loop, Hanoi, 


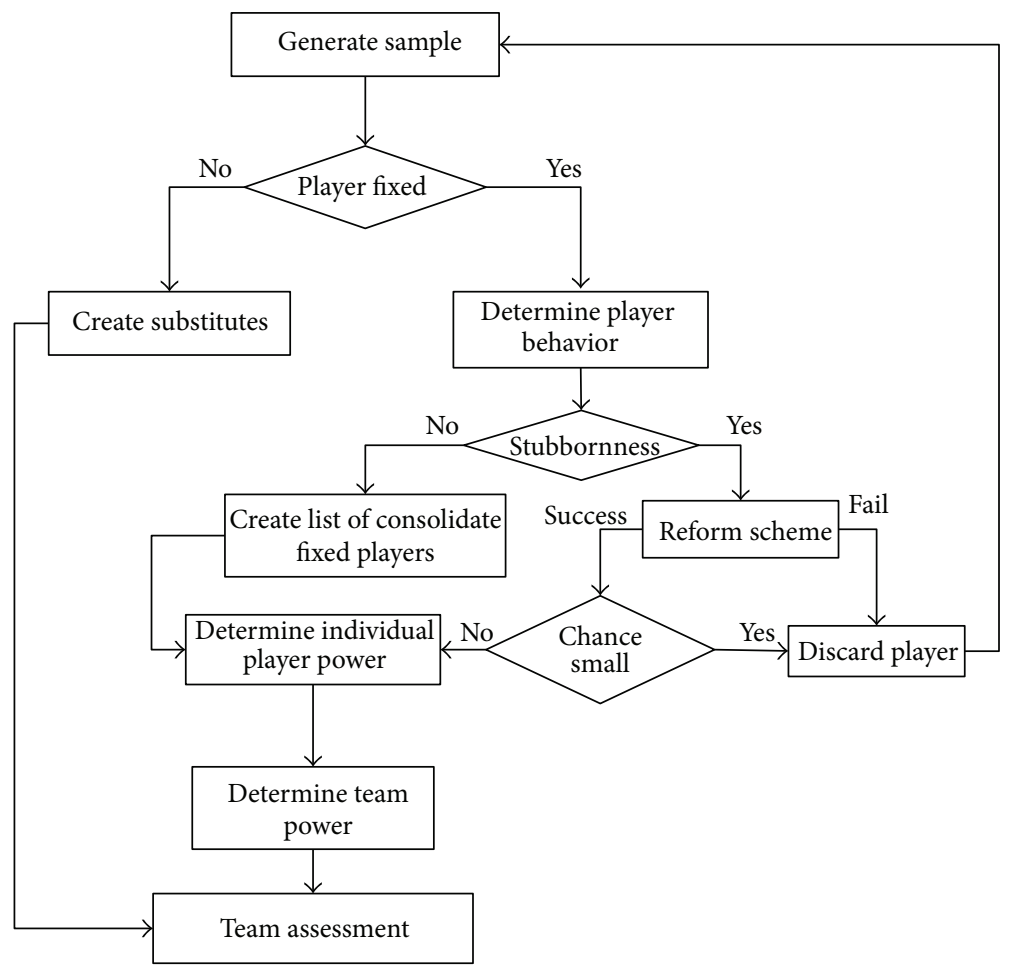

FIGURE 1: Modified soccer league algorithm flow chart.

TABLE 1: Control parameters choice and average values.

\begin{tabular}{lcc}
\hline Parameter & Initial/manual value & Average computational value \\
\hline$\gamma$ & 0.1 & 0.821 \\
$\beta$ & $30 \%$ of $b$ & $51 \%$ of $b$ \\
$\alpha$ & $2 \%$ & $45.9 \%$ \\
\hline
\end{tabular}

and New York Tunnels water networks, are used to test the performance of the modified heuristic. Computations are executed in MATLAB environment on a PC with AMD E300 APU with RadeonTM @1.30 GHz and 4.00 GB RAM. A total of 100 runs are performed for each problem recording the number of evaluations and the optimal cost.

The control parameters are $\alpha, \gamma$, and $\beta$. Sequential Parameter Optimization (SPO) introduced by Bartz-Beielstein et al. [27] is used to tune the parameters. The algorithm is allowed to perform a total of 1000 tests and is repeated 50 times. An initial population of 100 is used. Table 1 presents the initial values of the parameters used to perform the tests and the average values that are then used in the computational experiments. It is noticed that there is an inverse relationship between $b$ and $\beta$; that is, as $b \rightarrow \infty$, then $\beta \rightarrow 0$.

3.1. Two-Loop Water Network. A two-loop network problem of Alperovits and Shamir [28] is considered. The problem has 1 reservoir, 7 nodes, and 8 pipes. Figure 2 is the diagrammatic presentation of the network. The pipes in the network, all of them, are $1000 \mathrm{~m}$ long. Table 3 shows the cost data of available pipe diameters in both inches and millimeters.
TABLE 2: Two-loop network node information.

\begin{tabular}{lcc}
\hline Nodes & Demand $\left(\mathrm{m}^{3} / \mathrm{h}\right)$ & Elevation $(\mathrm{m})$ \\
\hline 1 & -1120 & 210 \\
2 & 100 & 150 \\
3 & 100 & 160 \\
4 & 120 & 155 \\
5 & 270 & 150 \\
6 & 330 & 165 \\
7 & 200 & 160 \\
\hline
\end{tabular}

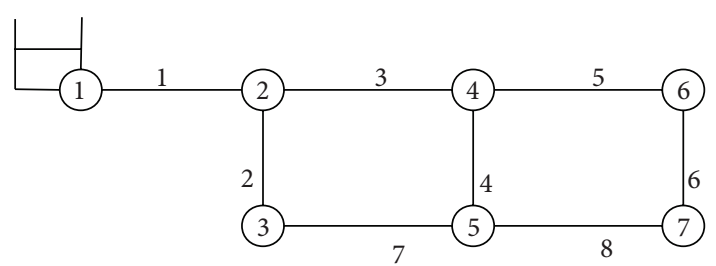

FIgURE 2: Two-loop water network.

Table 2 shows the node information of the network. The results are compared to those of genetic algorithm (GA) [14], simulated annealing algorithm (SA) [15], shuffled leapfrog algorithm (SLA) [13], shuffled complex algorithm (SCA) [16], modified genetic algorithm [17], particle swarm optimization (PSO) [18], differential evolution (DE) [19], harmony search (HS) [12], scatter search (SS) [21], PSO + DE [18], particle swarm harmony search (PSHS) [20], and SLC [11]. 


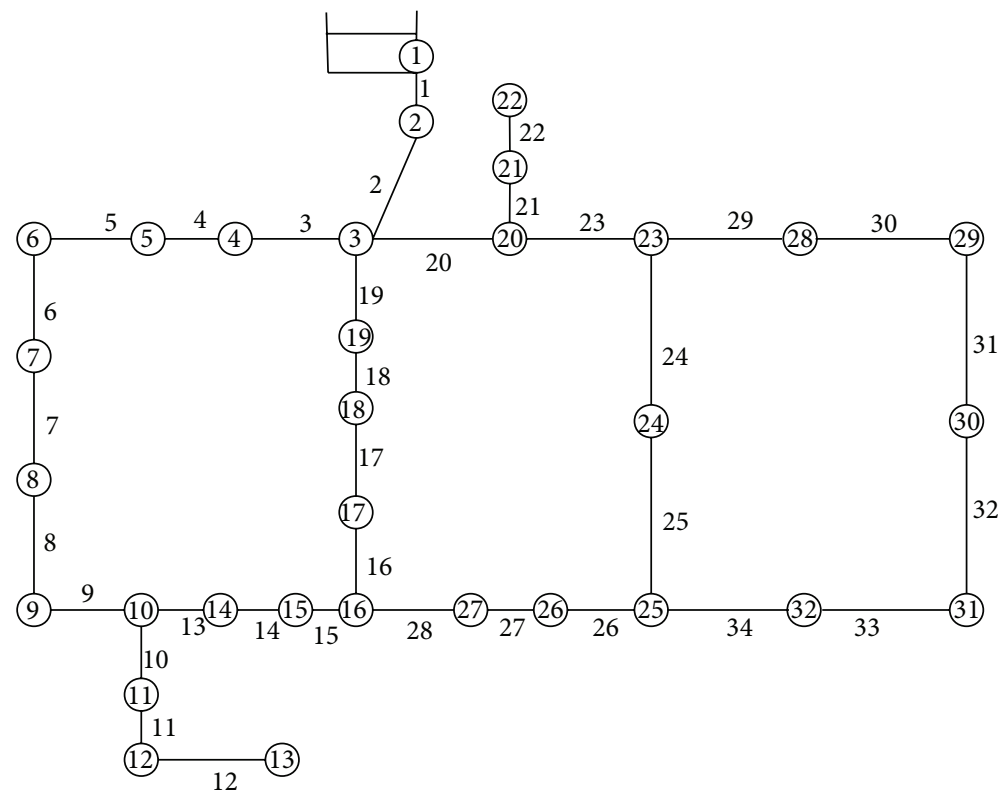

FIGURE 3: Hanoi water networkt.

TABle 3: Cost and diameter information for the two-loop water network.

\begin{tabular}{lcc}
\hline Diameter (in) & Diameter $(\mathrm{mm})$ & Cost $(\$ / \mathrm{m})$ \\
\hline 1 & 25.4 & 2 \\
2 & 50.8 & 5 \\
3 & 76.2 & 8 \\
4 & 101.6 & 11 \\
6 & 152.4 & 16 \\
8 & 203.2 & 23 \\
10 & 254 & 32 \\
12 & 304.8 & 50 \\
14 & 355.6 & 60 \\
16 & 406.4 & 90 \\
18 & 457.2 & 130 \\
20 & 508 & 170 \\
22 & 558.8 & 300 \\
24 & 609.6 & 550 \\
\hline
\end{tabular}

The computational results of the two-loop network are shown in Table 4 . The modified soccer league algorithm that uses stubborn players performs better in terms of average number of evaluations (1031) as compared to other heuristics, especially, the soccer league competition algorithm. As reported in Moosavian [11], the optimal costs (\$419 000) are exactly the same for all the algorithms.

3.2. Hanoi Water Network. The Hanoi network layout is shown by Figure 3. The network has 34 pipes, 32 nodes, of which one is a reservoir, and 3 loops. Table 5 presents the node and pipe data and Table 6 presents the cost information as described by Fujiwara and Khang [29]. There are $2.87 \times$ $10^{26}$ possible designs and 6 commercially available diameters.
TABLE 4: Results obtained by different metaheuristics for two-loop network.

\begin{tabular}{lcc}
\hline Algorithm & Mean evaluations & Cost (\$) \\
\hline GA [14] & 65000 & 419000 \\
SA [15] & 25000 & 419000 \\
SLA [13] & 11155 & 419000 \\
SCA [16] & 11019 & 419000 \\
Modified genetic algorithm [17] & 2440 & 419000 \\
PSO [18] & 5138 & 419000 \\
DE [19] & 4750 & 419000 \\
HS [20] & 2891 & 419000 \\
SS [21] & 3215 & 419000 \\
PSO + DE [18] & 3080 & 419000 \\
PSHS [20] & 233 & 419000 \\
SLC [11] & 2051 & 419000 \\
Modified soccer league algorithm & 1031 & 419000 \\
\hline
\end{tabular}

The modified soccer league algorithm is compared to MaxMin Ant System (MMAS) [22], PSO [18], hybrid discrete dynamically dimensioned search (HD-DDS) [23], genetic algorithm pipe network optimization model (GENOME) [24], genetic heritage evolution by stochastic transmission (GHEST) [25], SS [21], DE [19], self-adaptive differential evolution (SADE) [26], and SLC [11].

The computational results are shown in Table 7 . The results show that the optimal cost is the same for all algorithms. The average evaluations required by the modified algorithm to find the optimal solution are 65443 , fewer than that of MMAS, HD-DDS, and SLC. It is important to note that the modified algorithm has a success rate of $100 \%$ for the 100 runs. The algorithm performs better than the SLC algorithm in particular. 
TABLE 5: The Hanoi network pipe and node data.

\begin{tabular}{|c|c|c|c|c|c|c|c|}
\hline Pipe & Length $(\mathrm{m})$ & Pipe & Length (m) & Node & Demand $\left(\mathrm{m}^{3} / \mathrm{h}\right)$ & Node & Demand $\left(\mathrm{m}^{3} / \mathrm{h}\right)$ \\
\hline 1 & 100 & 18 & 800 & 1 & -19940 & 18 & 1345 \\
\hline 2 & 1350 & 19 & 400 & 2 & 890 & 19 & 60 \\
\hline 3 & 900 & 20 & 2200 & 3 & 850 & 20 & 1275 \\
\hline 4 & 1150 & 21 & 1500 & 4 & 130 & 21 & 930 \\
\hline 5 & 1450 & 22 & 500 & 5 & 725 & 22 & 485 \\
\hline 6 & 450 & 23 & 2650 & 6 & 1005 & 23 & 1045 \\
\hline 7 & 850 & 24 & 1230 & 7 & 1350 & 24 & 820 \\
\hline 8 & 850 & 25 & 1300 & 8 & 550 & 25 & 170 \\
\hline 9 & 800 & 26 & 850 & 9 & 525 & 26 & 900 \\
\hline 10 & 950 & 27 & 300 & 10 & 525 & 27 & 370 \\
\hline 11 & 1200 & 28 & 750 & 11 & 500 & 28 & 290 \\
\hline 12 & 3500 & 29 & 1500 & 12 & 560 & 29 & 360 \\
\hline 13 & 800 & 30 & 2000 & 13 & 940 & 30 & 360 \\
\hline 14 & 500 & 31 & 1600 & 14 & 615 & 31 & 105 \\
\hline 15 & 550 & 32 & 150 & 15 & 280 & 32 & 805 \\
\hline 16 & 2730 & 33 & 860 & 16 & 310 & - & - \\
\hline 17 & 1750 & 34 & 950 & 17 & 865 & - & - \\
\hline
\end{tabular}

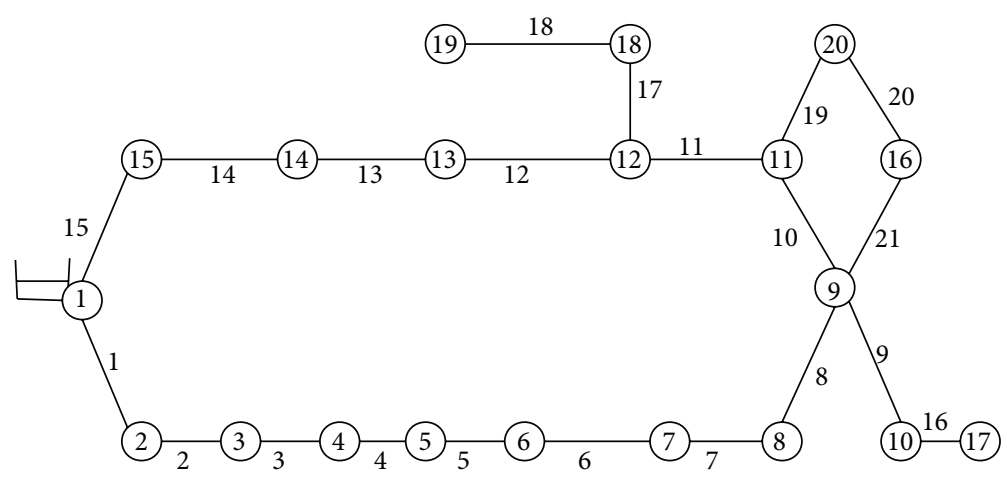

FIgURE 4: New York Tunnels water network.

TABLE 6: The cost data of the Hanoi network.

\begin{tabular}{lc}
\hline Diameter (inches) & Cost per unit length (unit) \\
\hline 12 & 45.726 \\
16 & 70.400 \\
20 & 98.387 \\
24 & 129.333 \\
30 & 180.748 \\
40 & 278.280 \\
\hline
\end{tabular}

3.3. New York Tunnels Network. The New York Tunnels city network was first presented by Neelakantan and Suribabu [17]. The network consists of 1 loop, 21 pipes, and 20 nodes as shown in Figure 4 . It is fed by gravity from a reservoir. Table 8 presents the pipe length and node data of the network. The search space of this optimization problem has $16^{21}=1.93 \times$ $10^{25}$ possible designs [33]. Available commercial diameters of the network and the respective costs are shown in Table 9.

The results are shown in Table 10 and 15311 average evaluations, lower than those of SLC, SS, and HD-DDS, produced the optimal cost of $\$ 38.64$ million. The best cost is found by the modified soccer league algorithm with an average success probability of $100 \%$ of 100 runs. A significant reduction in the mean evaluations from 15764 of SLC to 15311 is worth noting.

Statistical analysis of the experimental results is performed in SPSS. Table 11 presents results of the Analysis of Variance (ANOVA). The results show that the results of the algorithms used are significantly different from each other. Nonparametric tests, as suggested by García et al. [34], are performed to analyse the behavior of the modified soccer league algorithm as compared to the other algorithms used in each experimental problem. Table 12 presents results of the Wilcoxon test. Best 30 results among the runs are selected and used to avoid the challenge of using high runs that may result in the statistical test to detect insignificant difference as significant. The results show that the modified algorithm outperformed all the other algorithms in all experimental problems.

An experiment has been carried out to understand the behavior of the modified algorithm as the input parameters 
TABLE 7: Computational results of the Hanoi network.

\begin{tabular}{lccc}
\hline Algorithm & Number of runs & Optimal cost (\$) & Mean evaluations \\
\hline MMAS [22] & 20 & 6134087 & 85600 \\
PSO [18] & 2000 & 6081087 & NA \\
HD-DDS [23] & 50 & 6081087 & 100000 \\
GENOME [24] & 10 & 6081087 & NA \\
GHEST [25] & 60 & 6081087 & 50134 \\
SS [21] & 100 & 6081087 & 43149 \\
DE [19] & 300 & 6081087 & 48724 \\
SADE [26] & 50 & 6081087 & 60532 \\
SLC [11] & 50 & 6081087 & 71789 \\
Modified soccer league algorithm & 100 & 6081087 & 68443 \\
\hline
\end{tabular}

TABle 8: Node and pipe information of the New York Tunnels network.

\begin{tabular}{lccccc}
\hline Node & Demand $\left(\mathrm{m}^{3}\right)$ & Minimum head $(\mathrm{ft})$ & Pipe & Length $(\mathrm{ft})$ & Existing diameter $(\mathrm{ft})$ \\
\hline 1 & -22018 & 300 & 1 & 11600 & 180 \\
2 & 92.4 & 255 & 2 & 19800 & 180 \\
3 & 92.4 & 255 & 3 & 7300 & 180 \\
4 & 255 & 4 & 8300 & 180 \\
5 & 88.2 & 255 & 5 & 8600 & 180 \\
6 & 88.2 & 255 & 7 & 19100 & 130 \\
7 & 88.2 & 255 & 8 & 9600 & 132 \\
8 & 88.2 & 255 & 9 & 9600 & 180 \\
9 & 88.2 & 255 & 10 & 11200 & 204 \\
10 & 170 & 255 & 11 & 14500 & 204 \\
11 & 1 & 255 & 13 & 12200 & 204 \\
12 & 170 & 255 & 14 & 24100 & 204 \\
13 & 117.1 & 255 & 15 & 15500 & 72 \\
14 & 117.1 & 255 & 16 & 26400 & 72 \\
15 & 92.47 & 260 & 17 & 31200 & 60 \\
16 & 92.4 & 272.8 & 18 & 24000 & 60 \\
17 & 170 & 255 & 19 & 14400 & 60 \\
19 & 57.5 & 255 & 20 & 38400 & 72 \\
20 & 117.1 & 255 & 21 & 26400 & \\
\end{tabular}

TABLE 9: New York Tunnels commercially available pipe diameters and their respective costs.

\begin{tabular}{lc}
\hline Diameter (in) & Cost (US\$/ft) \\
\hline 36 & 93.5 \\
48 & 134 \\
60 & 176 \\
72 & 221 \\
84 & 267 \\
96 & 316 \\
108 & 365 \\
120 & 417 \\
132 & 469 \\
144 & 522 \\
156 & 577 \\
168 & 632 \\
180 & 689 \\
192 & 746 \\
204 & 804 \\
\hline
\end{tabular}

change. Unlike the SLC algorithm which uses the number of teams, fixed players, and substitutes as input parameters only, the modified algorithm uses the utility benefit of individual player, as a percentage, $U_{j}$, the utility function of the team, as a percentage, $U_{i}$, and the number of fixed players as additional input parameters. Table 13 shows the summary of computational results in terms of number of evaluations (Evalu), optimal cost (cost), and the computational time (run time).

It is shown that if both percentage benefits of the fixed player and team are high and the number of fixed players is high, the number of evaluations is reduced significantly. The computational time is as well reduced significantly. This might be as a result of the fact that the set of fixed players constructed by the algorithm eliminate those that are stubborn and concentrate only on players that are motivated by benefits they will get for winning the match. Fixed players that cost the team are penalised and eliminated from calculating the team power. The modified algorithm becomes more reliable and efficient by increasing the number of fixed players. 
TABLE 10: Computational results of the New York Tunnels network.

\begin{tabular}{lccc}
\hline Algorithm & Number of runs & Best cost (\$) & Mean evaluations \\
\hline MMAS [22] & 20 & 38.64 & 30700 \\
PSO [18] & 2000 & 38.64 & NA \\
HD-DDS [23] & 50 & 38.64 & 47000 \\
GHEST [25] & 60 & 38.64 & 11464 \\
SS [21] & 100 & 38.64 & 57583 \\
DE [19] & 50 & 38.64 & 5494 \\
SADE [26] & 50 & 38.64 & 6598 \\
SLC [11] & 100 & 38.64 & 15764 \\
Modified soccer league algorithm & 100 & 38.64 & 15311 \\
\hline
\end{tabular}

TABLE 11: ANOVA results of the three experimental problems.

\begin{tabular}{lccc}
\hline Problem & Definition & Degrees of freedom & $p$ value \\
\hline \multirow{3}{*}{ Two-loop } & Between group & 12 & 1288 \\
& Within groups & 1300 & 0.002 \\
& Total & 9 & \\
\multirow{2}{*}{ Hanoi } & Between group & 991 & 0.037 \\
& Within groups & 1000 \\
\hline \multirow{2}{*}{ New York } & Total & 8 & 0.041 \\
& Between group & 892 \\
\hline
\end{tabular}

TABLE 12: Wilcoxon test of the experimental problems.

\begin{tabular}{|c|c|c|c|c|c|c|c|c|c|}
\hline \multirow{2}{*}{ Proposed algorithm versus } & \multicolumn{3}{|c|}{ Two-loop } & \multicolumn{3}{|c|}{ Hanoi } & \multicolumn{3}{|c|}{ New York } \\
\hline & $R^{+}$ & $R^{-}$ & $p$ & $R^{+}$ & $R^{-}$ & $p$ & $R^{+}$ & $R^{-}$ & $p$ \\
\hline GA [27] & 210 & 88 & 0.001 & - & - & - & - & - & - \\
\hline SA [28] & 120 & 36 & 0.012 & - & - & - & - & - & - \\
\hline SLA [13] & 123 & 37 & 0.033 & - & - & - & - & - & - \\
\hline SCA [14] & 144 & 41 & 0.002 & - & - & - & - & - & - \\
\hline Modified genetic algorithm [15] & 101 & 29 & 0.011 & - & - & - & - & - & - \\
\hline PSO $[16]$ & 111 & 33 & 0.012 & 93 & 24 & 0.002 & 119 & 89 & 0.003 \\
\hline DE [17] & 213 & 56 & 0.03 & 117 & 34 & 0.021 & 144 & 47 & 0.034 \\
\hline HS [19] & 122 & 37 & 0.041 & - & - & - & - & - & - \\
\hline SS [18] & 144 & 54 & 0.032 & 127 & 51 & 0.043 & 154 & 71 & 0.011 \\
\hline $\mathrm{PSO}+\mathrm{DE}[16]$ & 123 & 77 & 0.037 & - & - & - & - & - & - \\
\hline PSHS [19] & 142 & 56 & 0.000 & - & - & - & - & - & - \\
\hline SLC [11] & 13 & 6 & 0.049 & 43 & 6 & 0.39 & 33 & 8 & 0.042 \\
\hline MMAS [20] & - & - & - & 134 & 67 & 0.001 & 89 & 23 & 0.003 \\
\hline HD-DDS [29] & - & - & - & 129 & 66 & 0.037 & 65 & 29 & 0.016 \\
\hline GENOME [22] & - & - & - & 178 & 50 & 0.045 & - & - & - \\
\hline GHEST [23] & - & - & - & 280 & 67 & 0.001 & 90 & 34 & 0.019 \\
\hline SADE [24] & - & - & - & 128 & 44 & 0.029 & 138 & 79 & 0.022 \\
\hline
\end{tabular}

\section{Conclusion}

This paper presented a modified soccer league algorithm by introducing stubborn fixed players. Each stubborn player is taken as a cost to the algorithm. Utility benefit of each individual fixed player and the team is used to calculate power of each fixed player. Probability of including a fixed player who has not reformed is also used to calculate the total team power. The algorithm is implemented to three benchmark problems and compared to the other algorithms available in the literature. The computational results show that the modified algorithm performs better than the SLC 
TABLE 13: Sensitivity analysis of the input parameters.

\begin{tabular}{|c|c|c|c|c|c|c|c|c|c|c|c|}
\hline \multicolumn{3}{|c|}{ Parameter } & \multicolumn{3}{|c|}{ Two-loop } & \multicolumn{3}{|c|}{ Hanoi } & \multicolumn{3}{|c|}{ New York } \\
\hline$U_{j}(\%)$ & $U_{i}(\%)$ & $N_{j}$ & Evalu & Cost & Run time & Evalu & Cost & Run time & Evalu & Cost & Run time \\
\hline 0 & 0 & 1 & 1900 & 419000 & 2.64 & 68500 & 6081087 & 4.02 & 15800 & 38.64 & 3.18 \\
\hline 5 & 5 & 2 & 1502 & 419000 & 2.33 & 68495 & 6081087 & 3.99 & 15792 & 38.64 & 3.04 \\
\hline 10 & 10 & 3 & 1465 & 419000 & 2.27 & 68490 & 6081087 & 3.56 & 15788 & 38.64 & 2.67 \\
\hline 20 & 20 & 4 & 1392 & 419000 & 2.12 & 68485 & 6081087 & 3.42 & 15781 & 38.64 & 2.55 \\
\hline 30 & 30 & 5 & 1109 & 419000 & 2.09 & 68480 & 6081087 & 3.37 & 15779 & 38.64 & 2.33 \\
\hline 40 & 40 & 6 & 1001 & 419000 & 1.73 & 68475 & 6081087 & 3.35 & 15768 & 38.64 & 2.21 \\
\hline 50 & 50 & 7 & 954 & 419000 & 1.65 & 68445 & 6081087 & 3.31 & 15765 & 38.64 & 2.15 \\
\hline 60 & 60 & 8 & 869 & 419000 & 1.62 & 68440 & 6081087 & 3.29 & 15742 & 38.64 & 2.08 \\
\hline 70 & 70 & 9 & 701 & 419000 & 1.45 & 68435 & 6081087 & 3.25 & 15703 & 38.64 & 2.01 \\
\hline 80 & 80 & 10 & 602 & 419000 & 1.37 & 68433 & 6081087 & 3.17 & 15596 & 38.64 & 2.00 \\
\hline 90 & 90 & 11 & 503 & 419000 & 1.28 & 68302 & 6081087 & 3.15 & 15584 & 38.64 & 1.98 \\
\hline 100 & 100 & 12 & 375 & 419000 & 1.24 & 68219 & 6081087 & 3.09 & 15347 & 38.64 & 1.85 \\
\hline & Mean & & 1031 & 419000 & 1.82 & 68433 & 6081087 & 3.41 & 15311 & 38.64 & 2.34 \\
\hline
\end{tabular}

algorithm in particular. It is also shown that the number of evaluations and computational time are reduced significantly as percentage benefits of both the player and team increase and the number of fixed players increases as well. It is recommended to increase the number of fixed players for the algorithm to be more reliable.

\section{Definitions of Terms}

$\pi: \quad$ Team benefit before bribe

$\delta\left(x_{j}\right)$ : Probability of successful reform $x$ attempt on player $j$

$\alpha$ : Fraction of the team benefits owned by the player outside the team

$\beta$ : $\quad$ Bonus for the player for winning a match

$\gamma$ : $\quad$ Stubbornness parameter that determines that the player's decision will be biased toward past decision

$\epsilon(j)$ : The probability that the stubborn player $i$ secures the fixed status

$\sigma: \quad$ Set of constraints

$\tilde{\eta}(\sigma)$ : Updated belief of the team management based on conditionally observing $\sigma$

$b$ : $\quad$ Bribe

$B_{m}$ : Team benefit for winning match $m$

$C_{m}$ : Team cost of losing the match $m$

$E$ : Outcome with the opportunist reformer as fixed player status

$F_{i, j}:$ Objective function

$H$ : $\quad$ Season benefit of the player for winning the championship

$i$ : $\quad$ Index denoting team

$j: \quad$ Index denoting player, $j \in J$

$m$ : Index denoting match

$N_{i}$ : Number of fixed player in a team, $i \in T$

$P_{i, j}: \quad$ Power of player

$Q_{j}$ : Outcome when the player $j$ cannot overrun the fixed player status
$R: \quad$ Outcome when a genuine reformer

successfully secures the fixed player status

T: Team

$U_{i}$ : Utility benefit of the team $i, i \in T$

$U_{j}$ : Utility benefit of the individual player $j$

$V$ : Genuine reformer benefit

$W_{m}$ : Won match $m$

$x_{j}$ : Maturity of reform $x$ on player $j$

$Y_{i}$ : Total power of team $i$.

\section{Competing Interests}

The authors declare that they have no competing interests.

\section{References}

[1] P. Wu, L. Gao, D. Zou, and S. Li, "An improved particle swarm optimization algorithm for reliability problems," ISA Transactions, vol. 50, no. 1, pp. 71-81, 2011.

[2] P.-Y. Yin, S.-S. Yu, P.-P. Wang, and Y.-T. Wang, “Task allocation for maximizing reliability of a distributed system using hybrid particle swarm optimization," Journal of Systems and Software, vol. 80, no. 5, pp. 724-735, 2007.

[3] L. D. S. Coelho, "An efficient particle swarm approach for mixed-integer programming in reliability-redundancy optimization applications," Reliability Engineering and System Safety, vol. 94, no. 4, pp. 830-837, 2009.

[4] D. Zou, L. Gao, S. Li, and J. Wu, "An effective global harmony search algorithm for reliability problems," Expert Systems with Applications, vol. 38, no. 4, pp. 4642-4648, 2011.

[5] W. Kuo and V. R. Prasad, "An annotated overview of systemreliability optimization," IEEE Transactions on Reliability, vol. 49 , no. 2, pp. 176-187, 2000.

[6] N. Dellaert, J. Jeunet, and N. Jonard, “Genetic algorithm to solve the general multi-level lot-sizing problem with time-varying costs," International Journal of Production Economics, vol. 68, no. 3, pp. 241-257, 2000. 
[7] A. S. Raza and A. Akgunduz, "A comparative study of heuristic algorithms on Economic Lot Scheduling Problem," Computers and Industrial Engineering, vol. 55, no. 1, pp. 94-109, 2008.

[8] R. Pitakaso, C. Almeder, K. F. Doerner, and R. F. Hartl, "A MAX-MIN ant system for unconstrained multi-level lot-sizing problems," Computers and Operations Research, vol. 34, no. 9, pp. 2533-2552, 2007.

[9] H. Yi, J.-H. Cai, I. Kaku, Y.-L. Li, Y.-Z. Chen, and J.-F. Tang, "Evolutionary algorithms for solving unconstrained multilevel lot-sizing problem with series structure," Journal of Shanghai Jiaotong University, vol. 17, no. 1, pp. 39-44, 2012.

[10] G. Chagwiza, B. C. Jones, and S. D. Hove-Musekwa, "Impact of new water sources on the overall water network: an optimisation approach," International Scholarly Research Notices, vol. 2014, Article ID 958650, 8 pages, 2014.

[11] N. Moosavian, "Soccer league competition algorithm for solving knapsack problems," Swarm and Evolutionary Computation, vol. 20, pp. 14-22, 2015.

[12] Z. W. Geem, J. H. Kim, and G. V. Loganathan, "Harmony search optimization: application to pipe network design," International Journal of Modelling and Simulation, vol. 22, no. 2, pp. 125-133, 2002.

[13] M. M. Eusuff and K. E. Lansey, "Optimization of water distribution network design using the shuffled frog leaping algorithm," Journal of Water Resources Planning and Management, vol. 129, no. 3, pp. 210-225, 2003.

[14] D. A. Savic and G. A. Walters, "Genetic algorithms for leastcost design of water distribution networks," Journal of Water Resources Planning and Management, vol. 123, no. 2, pp. 67-77, 1997.

[15] M. Da Conceição Cunha and J. Sousa, "Water distribution network design optimization: simulated annealing approach," Journal of Water Resources Planning and Management, vol. 125, no. 4, pp. 215-221, 1999.

[16] S. Y. Liong and M. Atiquzzaman, "Optimal design of water distribution network using shuffled complex evolution," Journal of the Institution of Engineers, vol. 44, no. 1, pp. 93-107, 2004.

[17] T. Neelakantan and C. R. Suribabu, "Optimal design of water distribution networks by a modified genetic algorithm," Journal of Civil and Environmental Engineering, vol. 1, no. 1, pp. 20-34, 2005.

[18] A. Sedki and D. Ouazar, "Hybrid particle swarm optimization and differential evolution for optimal design of water distribution systems," Advanced Engineering Informatics, vol. 26, no. 3, pp. 582-591, 2012.

[19] C. R. Suribabu, "Differential evolution algorithm for optimal design of water distribution networks," Journal of Hydroinformatics, vol. 12, no. 1, pp. 66-82, 2010.

[20] Z. W. Geem, "Particle-swarm harmony search for water network design," Engineering Optimization, vol. 41, no. 4, pp. 297311, 2009.

[21] M.-D. Lin, Y.-H. Liu, G.-F. Liu, and C.-W. Chu, "Scatter search heuristic for least-cost design of water distribution networks," Engineering Optimization, vol. 39, no. 7, pp. 857-876, 2007.

[22] A. C. Zecchin, H. R. Maier, A. R. Simpson, M. Leonard, A. J. Roberts, and M. J. Berrisford, "Application of two ant colony optimisation algorithms to water distribution system optimisation," Mathematical and Computer Modelling, vol. 44, no. 5-6, pp. 451-468, 2006.

[23] B. A. Tolson, M. Asadzadeh, H. R. Maier, and A. C. Zecchin, "Hybrid discrete dynamically dimensioned search(HD-DDS) algorithm for water distribution system design optimization," Water Resource Research, vol. 45, no. 12, pp. 1-15, 2009.

[24] J. Reca and J. Martínez, "Genetic algorithms for the design of looped irrigation water distribution networks," Water Resources Research, vol. 42, no. 5, Article ID W05416, 2006.

[25] A. Bolognesi, C. Bragalli, A. Marchi, and S. Artina, "Genetic heritage evolution by stochastic transmission in the optimal design of water distribution networks," Advances in Engineering Software, vol. 41, no. 5, pp. 792-801, 2010.

[26] F. Zheng, A. C. Zecchin, and A. R. Simpson, "Self-adaptive differential evolution algorithm applied to water distribution system optimization," Journal of Computing in Civil Engineering, vol. 27, no. 2, pp. 148-158, 2013.

[27] T. Bartz-Beielstein, C. W. G. Lasarczyk, and M. Preuss, "Sequential parameter optimization," in Proceedings of the IEEE Congress on Evolutionary Computation (CEC '05), vol. 1, pp. 773-780, IEEE, September 2005.

[28] E. Alperovits and U. Shamir, "Design of optimal water distribution systems," Water Resources Research, vol. 13, no. 6, pp. 885900, 1977.

[29] O. Fujiwara and D. B. Khang, "A two-phase decomposition method for optimal design of looped water distribution networks," Water Resources Research, vol. 26, no. 4, pp. 539-549, 1990.

[30] M. Chiarandini, L. Paquete, M. Preuss, and E. Ridge, "Experiments on metaheuristics: methodological overview and open issues," Tech. Rep. DMF- 2007-03-003, The Danish Mathematical Society, Copenhagen, Denmark, 2007.

[31] E. Osaba, R. Carballedo, F. Diaz, E. Onieva, and A. Perallos, "A proposal of good practice in the formulation and comparison of meta-heuristics for solving routing problems," in International Joint Conference SOCO'14-CISIS'14-ICEUTE'14, J. G. de la Puerta, I. G. Ferreira, P. G. Bringas et al., Eds., vol. 299 of Advances in Intelligent Systems and Computing, pp. 31-40, Springer, 2014.

[32] C. McGeoch, "Experimental analysis of algorithms," in Handbook of Global Optimisation, vol. 2, Kluwer Academic, New York, NY, USA, 2002.

[33] Z. W. Geem, "Optimal cost design of water distribution networks using harmony search," Engineering Optimization, vol. 38, no. 3, pp. 259-280, 2006.

[34] S. García, D. Molina, M. Lozano, and F. Herrera, "A study on the use of non-parametric tests for analyzing the evolutionary algorithms' behaviour: a case study on the CEC'2005 Special Session on Real Parameter Optimization," Journal of Heuristics, vol. 15, no. 6, pp. 617-644, 2009. 


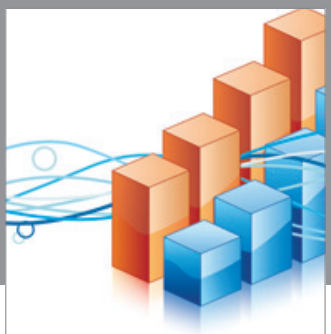

Advances in

Operations Research

vatem alat4

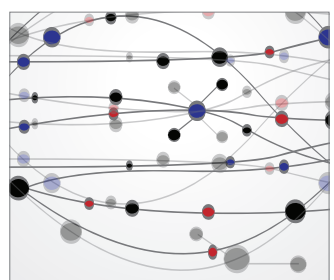

\section{The Scientific} World Journal
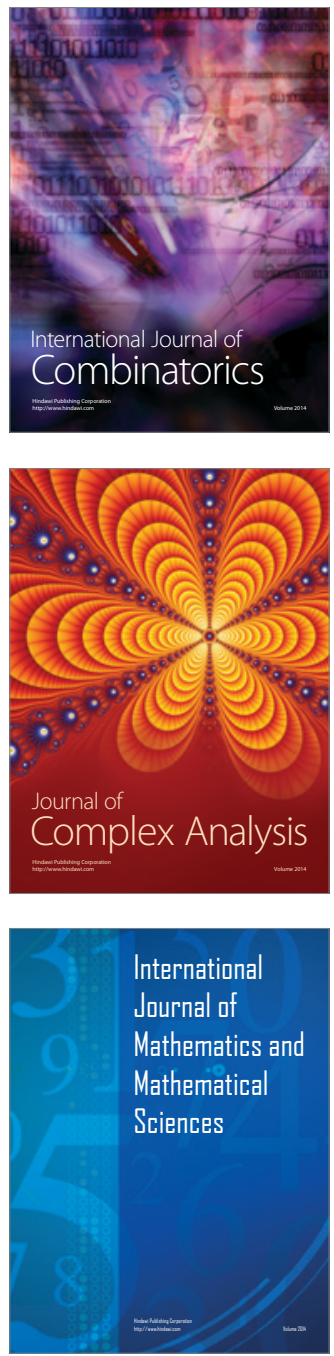
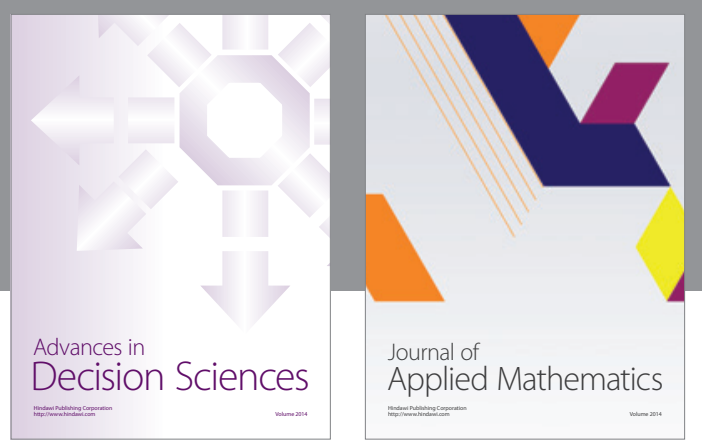

Algebra

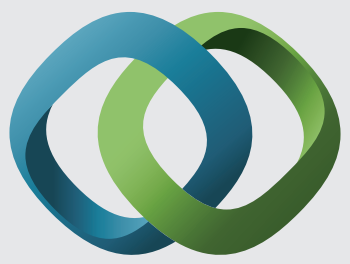

\section{Hindawi}

Submit your manuscripts at

http://www.hindawi.com
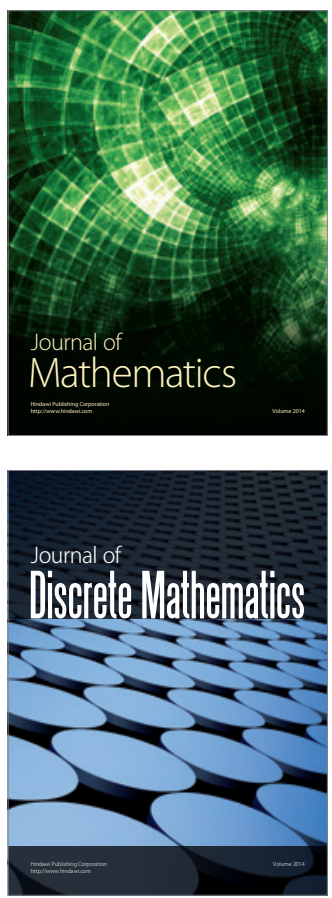

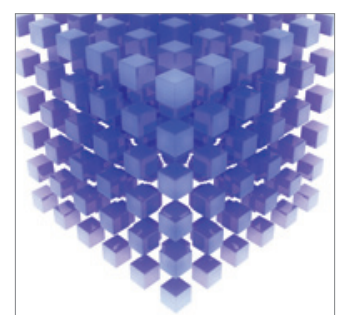

Mathematical Problems in Engineering
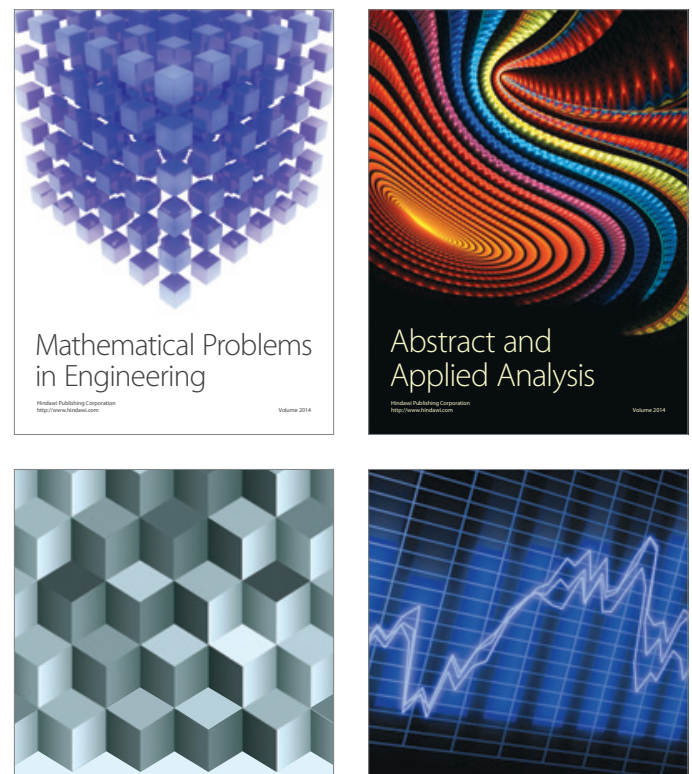

Journal of

Function Spaces

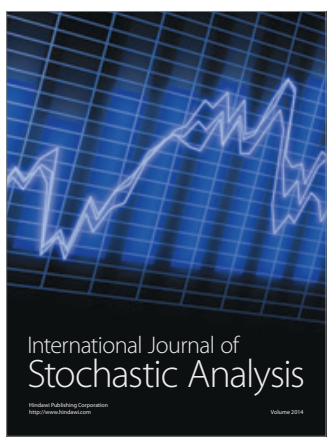

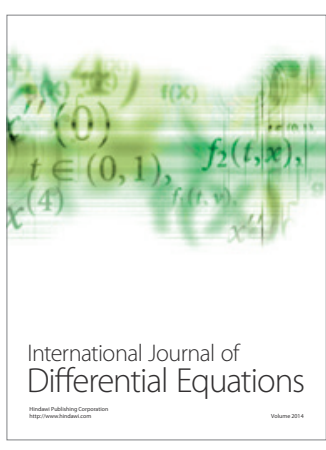
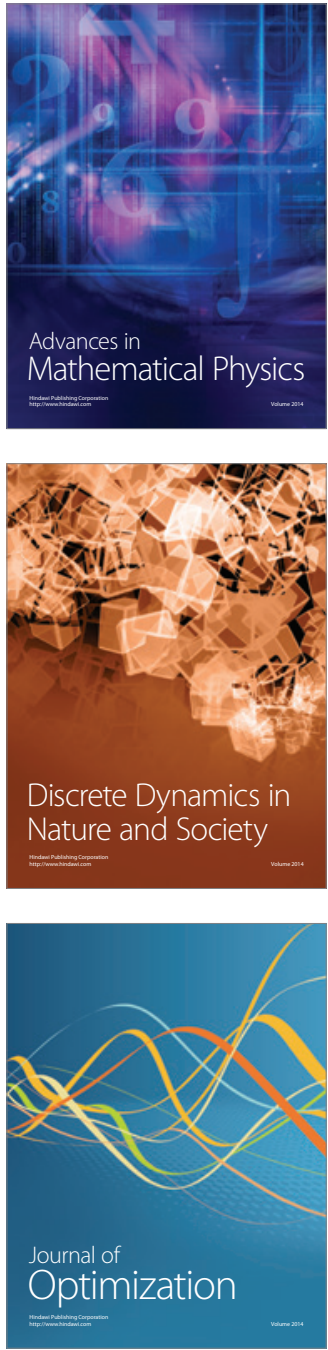